\title{
A Case of Maturing Perineal Lipoblastoma in an Infant
}

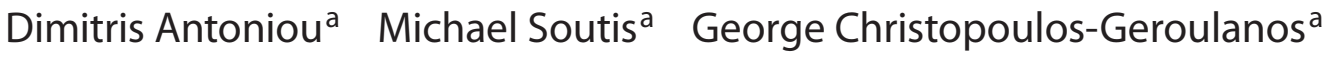 \\ Kalliopi Stefanaki ${ }^{b}$

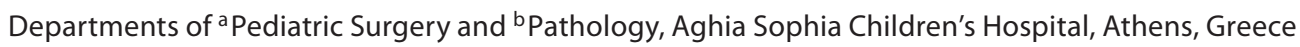

\section{Key Words}

Perineal lipoblastoma • Lipoma • Myxoid liposarcoma •

Lipoblastomatosis $\cdot$ Infant

\begin{abstract}
Objective: To report the unusual occurrence of a perineal lipoblastoma presenting as a painless enlarging mass in an infant. Case Presentation and Intervention: A 7-month-old boy presented with a 6-month history of an asymptomatic progressively enlarging perineal mass. Imaging studies were unable to provide a diagnosis. Complete resection of the mass was achieved and there was no recurrence at 18-month follow-up. Histopathologic findings were consistent with a maturing perineal lipoblastoma. Conclusion: This case report serves as a reminder to physicians and especially pediatric surgeons to consider perineal lipoblastoma in the differential diagnosis of soft tissue perineal masses in infancy.
\end{abstract}

Copyright $\odot 2009$ S. Karger AG, Basel

\section{Introduction}

Adipose tumors represent about $6 \%$ of all soft tissue neoplasms found in pediatric patients. The prevalence of lipoblastoma among the adipose tumors is approximately $20-30 \%$ and lipoblastomas constitute only $3 \%$ of all soft tissue tumors in the first year of life [1]. A peri- neal location is exceedingly rare and to date, only 5 cases of perineal lipoblastoma in the pediatric age group have been reported in the English language literature [2-6]. We report a rare case of perineal lipoblastoma in a 7-month-old boy presenting as a rapidly enlarging mass.

\section{Case Report}

A 7-month-old boy was referred to our hospital with a soft tissue mass in the perineal region. His parents first noticed a swelling in the child's perineum at 1 month of age. No trauma, pain or discharge related to the swelling was reported. Over the next 6 months the size of the lesion progressively increased in size, but was asymptomatic. Physical examination revealed a nontender, rounded, perineal mass measuring approximately $3.5 \times 3.0 \mathrm{~cm}$. No overlying skin changes were noted, both testes were fully descended and palpable. Abdominal and rectal examinations were unremarkable. Ultrasonography demonstrated a heterogeneous lesion without calcification and poor blood flow. The sonolucency was consistent with fat and no intra-abdominal associated anomaly was detected. Magnetic resonance imaging (MRI) revealed a well-defined soft tissue mass, with a high signal intensity on $\mathrm{T}_{1}$ - and $\mathrm{T}_{2}$-weighted images. Laboratory investigations including C-reactive protein, alpha-fetoprotein and human chorionic gonadotropin were within the normal limits. With a presumed diagnosis of lipoblastoma the patient was taken to the operating room. At surgery, a lobulated, yellow fatty mass was identified and gross total resection was performed (fig. 1).

The postoperative course was uneventful. The patient is without evidence of recurrence at 18 months. Histopathologic exami-

\section{KARGER}

Fax +41613061234 E-Mail karger@karger.ch www.karger.com
(C) 2009 S. Karger AG, Basel

$1011-7571 / 09 / 0184-0335 \$ 26.00 / 0$

Accessible online at:

www.karger.com/mpp
Dimitris Antoniou

$48 \mathrm{Ag}$. Meletiou Street

GR-11257 Athens (Greece)

Tel. +30 210646 3600, Fax +30 6944773370

E-Mail dcantoniou@hotmail.com 


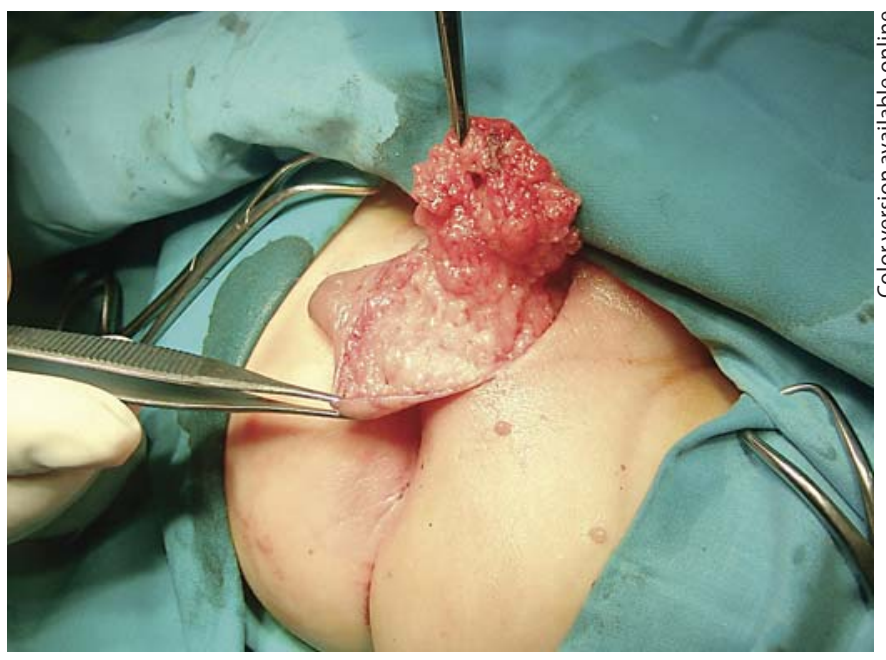

Fig. 1. Intraoperative image showing a lobulated, fatty, soft tissue mass.

Fig. 2. a Lipoblastoma with obvious fibrous septa delineating lobules of mature and immature fat cells (inset upper left corner). Hematoxylin-eosin. $\times 200$. b Immunohistochemical expression of CD34 in fibrous septa and in the endothelial cells of sinusoids in the fat lobules. Streptavidin-biotin HRP. $\times 200$.

nation of the resected specimen showed a $3.5 \times 3 \times 2 \mathrm{~cm}$ yellow, soft and lobulated mass without necrosis and hemorrhage. Microscopically, the mass was composed of small lobules of mature and immature fat cells, separated by fibrous septa containing small blood vessels and collagen (fig. 2a).

The adipocytes were most prominent in the central portion of the lobule. The immunohistochemical investigation showed expression of CD34 in the fibroblastic cells of the septa (fig. 2b). Based on the histopathological examination, the diagnosis of maturing lipoblastoma was rendered.

\section{Discussion}

Lipoblastoma is a rare, benign mesenchymal tumor that develops from embryonic remnants of white adipose tissue. This tumor primarily occurs in infancy $(75 \%<1$ year) and early childhood ( $90 \%<3$ years), accounting for $<1 \%$ of all childhood neoplasms [1]. This tumor usually presents in superficial tissues of the extremities, although
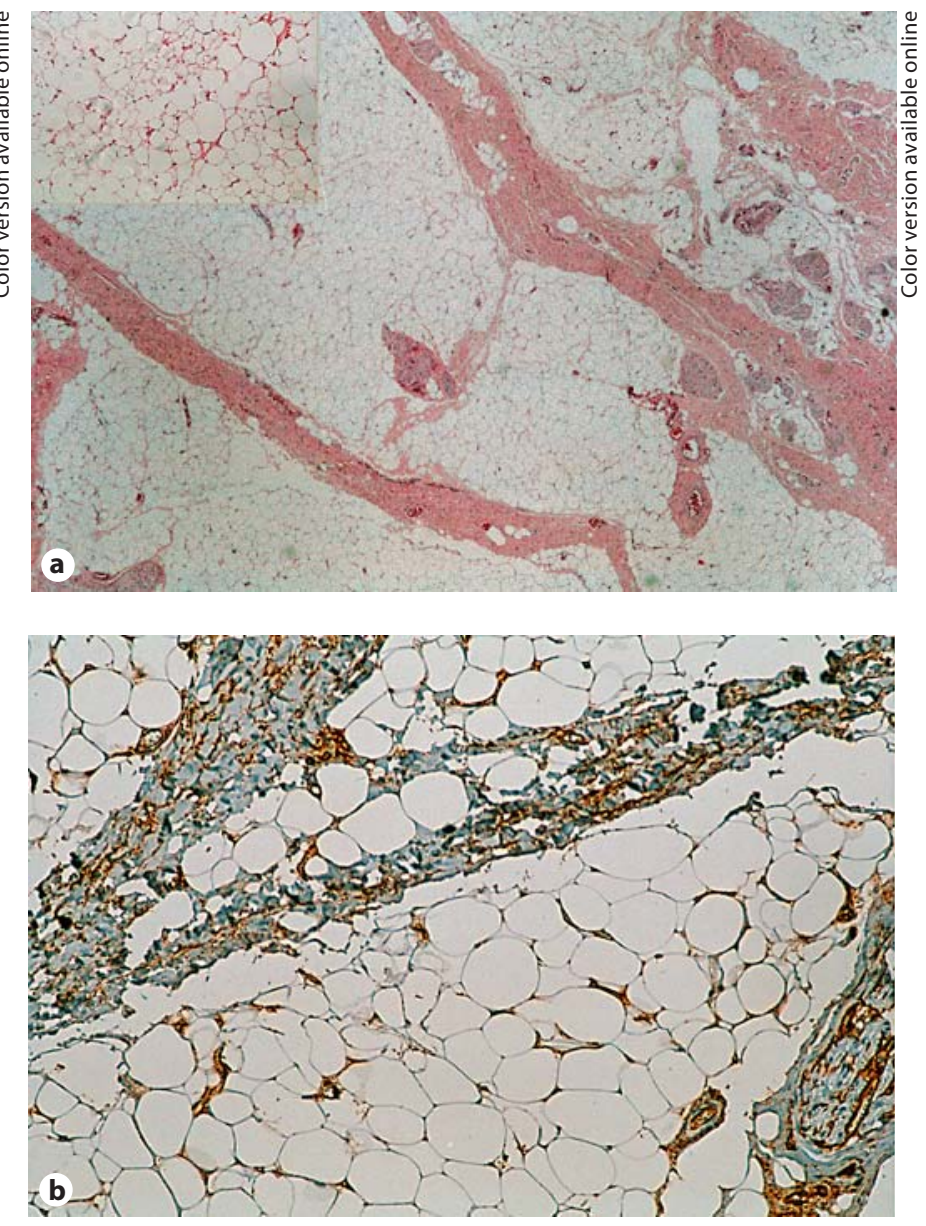

the mediastinum, trunk, retroperitoneum, and head and neck may be affected [3]. However, perineal location is extremely uncommon. To date only 5 cases of perineal lipoblastoma have been reported in the pediatric age group (table 1). The age range of the 6 perineal lipoblastomas (including the current case) is from 9 days to 30 months with a male predilection (4 males and 2 females). As in our case, they are usually capsular, grossly circumscribed, but a noncapsulated, diffuse type with the tendency to infiltrate adjacent tissues is referred as lipoblastomatosis. Most cases are asymptomatic, and present as a slowly enlarging soft tissue masses. In our patient, the tumor presented as a nonerythematous painless mass in the perineum that continued to enlarge over several months. Accurate preoperative diagnosis of lipoblastoma is rarely made. Many diagnostic imaging studies are available, but none of them can give a definitive diagnosis, they only suggest likely diagnosis as in our case. Ultrasonography, computed tomography and MRI all pro- 
Table 1. Clinical data of perineal lipoblastomas reported in the English language literature

\begin{tabular}{lllllll}
\hline Reference & Age & Sex & Size, cm & Treatment & $\begin{array}{l}\text { Postoperative } \\
\text { diagnostic method }\end{array}$ & Recurrence \\
\hline 2 & 2 months & female & $4.0 \times 2.0 \times 1.5$ & surgery & histopathology & not reported \\
3 & 18 days & female & not reported & surgery & not reported & no \\
4 & 9 days & male & 3.0 & surgery & histopathology & not reported \\
5 & 18 months & male & $4.0 \times 0.12$ & surgery & cytogenetics & yes \\
6 & 30 months & male & - & surgery & histopathology & yes \\
Present case & 7 months & male & $3.5 \times 3.0$ & surgery & histopathology & no \\
\hline
\end{tabular}

vide useful information regarding the position, depth and anatomical relationships of the lesion and complement each other, but seldom, however, can determine whether a tumor is benign or malignant. Although reports in children are limited, MR imaging is considered the best method for the evaluation of benign fatty tumors [7].

Our patient was operated on with the possible diagnosis of perineal lipoma, on the basis of physical examination, MRI findings, and laboratory tests, but histopathology was essential in order to establish the diagnosis. The histopathological findings of the presence of lobular organization of adipocytes and foci of fat tissue were helpful in distinguishing lipoblastoma from other adipose tissue tumors like lipoma and fibrolipoma. Lipoblastoma is characterized by small lobules of mature and immature fat cells separated by fibrous septa with or without a myxoid stroma. In lipoblastomatosis the lobular pattern is less pronounced [8]. On the other hand hibernoma displays a lobular pattern but consists entirely of brown fat cells, which was not the case [9].

Occasionally, especially in older children, it could be difficult to distinguish a lipoblastoma from myxoid liposarcoma, which is characterized by lack of lobulation with mature fat cells concentrated in the periphery of the lobule, whereas in lipoblastoma fat cells are concentrated in the central portion of the lobule [9].

In histologically borderline cases cytogenetics can be used as a diagnostic tool in differentiating lipoblastoma from myxoid or well-differentiated liposarcomas and other adipose tumors [10]. To our knowledge, only in 1 case of perineal lipoblastoma cytogenetic analysis was needed in order to establish the diagnosis, as shown in table 1 [5]. In the current case the age of the patient, the clinical presentation and the histopathological evaluation provided a definitive diagnosis, and sophisticated molecular and cytogenetic studies were not necessary.
Although a 'wait and see' approach has been suggested, the treatment of choice is complete surgical excision [11]. Despite the potential rapid growth and local invasion, the prognosis of lipoblastoma is excellent. In the current patient complete resection of the tumor was undertaken as the definitive treatment and for diagnosis of the perineal mass. When complete excision is not obtained, MRI is useful for follow-up and evaluation of possible recurrent lesions [3]. Malignant degeneration has never been documented, but a follow-up period of at least 5 years is recommended because recurrence has been reported to occur as long as 8 years postoperatively [12]. The recurrence rate reported is between 0 and $25 \%$, with an average time to recurrence of 3 years, and recurrence usually occurs in lipoblastomatosis [10]. Patients with focal lipoblastoma are unlikely to require further operative intervention. Our patient is currently asymptomatic and tumor-free 18 months after surgery.

\section{Conclusion}

This report points out the unusual location of maturing lipoblastoma in the perineum. Accurate preoperative diagnosis of lipoblastoma is rarely made with clinical and imaging examination. In ambiguous cases, molecular and cytogenetic studies may be necessary. Complete surgical excision is the definitive treatment.

References

Med Princ Pract 2009;18:335-338 337 matosis: an analysis of 35 cases. Cancer 1973; 32:482-492.

2 Tsai H, Whitney K, Kogan S: Perineal lipoblastoma in a neonate. J Urol 1997;158:22722273.

-3 McVay MR, Keller JE, Wagner CW, Jackson RJ, Smith SD: Surgical management of lipoblastoma. J Pediatr Surg 2006;41:1067-1071. 
4 Ito M, Hashizume K, Kanamori Y: New phenotype of accessory scrotum with perineal lipoblastoma: coexistence of midperineal and lateral accessory scrotums. Int J Urol 2004;11:125-127.

5 Moreiro C, Rapella A, Rosanda C, Tassano E: PLAG1-HAS2 fusion in lipoblastoma with masked $8 \mathrm{q}$ intrachromosomal rearrangement. Cancer Genet Cytogenet 2005;156: 183-184.

$\checkmark 6$ Al-Momani HM: Recurrent maturing perineal lipoblastoma. Saudi Med J 2005;26: 1815-1817.
7 Ha TV, Kleinman PK, Fraire A, Spevak MR, Nimkin K, Cohen IT, Hirsch M, Walton R MR imaging of benign fatty tumors in children: report of four cases and reviewed of the literature. Skeletal Radiol 1994;23:361-367.

8 Hicks J, Dilley A, Patel D, Barrish J, Zhu SH, Brandt M: Lipoblastoma and lipoblastomatosis in infancy and childhood: histopathologic, ultrastructural and cytogenetic features. Ultrastruct Pathol 2001;25:321-333.

$\checkmark 9$ Dilley AV, Patel DL, Hicks MJ, Brand ML: Lipoblastoma: pathophysiology and surgical management. J Pediatr Surg 2001;36:229231.
10 Speer AL, Schofield DE, Wang KS, Shin CE, Stein JE, Shaul DB, Mahour GH, Ford HR: Contemporary management of lipoblastoma. J Pediatr Surg 2008;43:1295-1300.

11 Mognato G, Cecchetto G, Carli M, Talenti E, D’Amore ESG, Pederzini F, Guglielmi M: Is surgical treatment of lipoblastoma always necessary? J Pediatr Surg 2000;35:15111513.

12 Jung SM, Chang PY, Luo CC, Huang CS, Lai JY, Hsueh C: Lipoblastoma/lipoblastomatosis: a clinicopathologic study of 16 cases in Taiwan. Pediatr Surg Int 2005;21:809-812.
Antoniou/Soutis/ Christopoulos-Geroulanos/Stefanaki 